\title{
PREDICTIVE SIMULATION OF DEFORMATION AND FAILURE OF PEAT-CALCAREOUS SOIL LAYERED GROUND DUE TO MULTISTAGE TEST EMBANKMENT LOADING
}

\author{
Toshihiro TAKaine ${ }^{\mathrm{i})}$, Mutsumi TAShiro ${ }^{\mathrm{ii})}$, TAkAhiko Shinna ${ }^{\mathrm{iii}}$, \\ Toshihiro NodA ${ }^{\text {iv) }}$ and AKIra AsAOKA ${ }^{\text {iv) }}$
}

\begin{abstract}
The continuous behaviour of a ground-embankment system from the stage of deformation up to failure was predicted with respect to an actual test embankment that had been constructed in stages on a soft ground made up of peat and calcareous soil. The behaviour prediction was carried out by employing soil-water coupled finite deformation analysis, which also included simulation of the embankment construction process. The information used in the analysis was limited to such things as the results of soil tests on soil materials (peat and calcareous soil) sampled from the ground, including their sensitivity ratios, and the embankment's construction history. The SYS Cam-clay model was used in the constitutive equations of the soils to determine the material constants of the soils and the initial conditions of the ground, and the computations were performed under plane strain conditions. As a result, the computed profiles of Wtype ground settlement and of slip surfaces running through the embankment were found to be in good overall agreement with the actual profiles measured at the site. Furthermore, we found that this slippage is attributable to the undrained shear response of the soil elements in the calcareous soil layer, where slippage begins to occur during embankment loading. In other words, the slippage is caused by the rapid softening behaviour caused by the degradation of structure after the effective stress ratio reaches the vicinity of the critical state line.
\end{abstract}

Key words: deformation, failure, sensitivity, soil structure, soil-water coupled analysis, SYS Cam-clay model (IGC: E2)

\section{INTRODUCTION}

The authors have been developing the ground analysis tool GEOASIA (Asaoka and Noda, 2007; Noda et al., 2008) based on the finite deformation theory of twophase soil-water coupled systems, which is also capable of accounting for inertial forces. For the elasto-plastic constitutive model of the soil skeleton, this analysis tool utilizes the SYS Cam-clay model (Asaoka et al., 2002), which is capable of accounting for the actions of the soil skeleton structure (structure, overconsolidation, anisotropy) due to plastic deformation. GEOASIA, unlike other exclusive analysis tools, such as those intended to investigate only consolidation behaviour, or failure analysis tools meant to investigate only ultimate bearing capacity problems, is capable of analyzing soil behaviour continuously from deformation up to failure (Asaoka et al., 1994, Noda et al., 2007), irrespective of whether the problem is dynamic or static (Asaoka and Noda, 2007; Noda et al., 2008). This paper details the results of analy- sis carried out by the authors utilizing this tool with respect to the blind test outlined below. The main objective of this paper is to illustrate the following three points through the analysis results obtained: 1) Like sand and clayey soils, the behaviour of even so-called problem soils such as peat and calcareous soils can be described within the theoretical framework of the SYS Cam-clay model. 2) The "sensitivity ratio," which is not usually employed in the analysis of soil behaviour, can be utilized as important data for determining the material constants of soils and the initial conditions of grounds. 3) With respect to the problem of controlling embankment loading, the analysis tool described in this work enables determination of the ultimate load with relatively good accuracy.

This blind test was planned at the Earth Forum held at Kyodai-Kaikan, Kyoto University, on November 18, 2006 in memory of Professor Toru Shibata. The task assigned in the blind test was prediction of the deformation behaviour (settlement profile of the ground surface, tem-

i) Manager, Asanuma Corporation, Osaka, Japan.

ii) Assistant Professor, Department of Civil Engineering, Nagoya University, Nagoya, Japan (mutsumi@civil.nagoya-u.ac.jp).

iii) Research Engineer, Institute of Technology, Penta-Ocean Construction Co., Ltd., Tochigi, Japan.

iv) Professor, Department of Civil Engineering, Nagoya University, Nagoya, Japan.

The manuscript for this paper was received for review on April 13, 2009; approved on December 2, 2009.

Written discussions on this paper should be submitted before November 1, 2010 to the Japanese Geotechnical Society, 4-38-2, Sengoku, Bunkyo-ku, Tokyo 112-0011, Japan. Upon request the closing date may be extended one month. 
poral variations of the lateral displacement profiles, etc.) and failure behaviour (thickness and failure profile of the embankment at the time of failure) of a ground-test embankment system using only some limited data regarding the ground and embankment, including the laboratory test results for remolded samples. The test embankment had been constructed in four stages on soft ground.

Analyses of the deformation behaviour of a ground due to structures built on it are usually classified into the following three categories (Lambe, 1973).

(1) Analysis using information regarding the ground obtained in advance

(2) Analysis using information obtained during construction to predict later behaviour (field observation method)

(3) Analysis using information obtained after construction ("autopsies")

According to the above classification, the blind test discussed here falls into the first category. On completion of the blind test, it was revealed that the site is in the Notec River valley of northwestern Poland (Wojciech et al., 1988a, b). The information made available for the blind test consisted of the test results of the physical properties and mechanical properties of soil samples extracted in advance from the soft ground made up of peat and calcareous soil, the soil sensitivity ratios being in the range of 7 to 12 , the profile of the test embankment, and its loading history. No other information regarding the embankment was made available except that it was made up of sandy soil.

In the computations, based on the information made available regarding the results of the tests of the physical and mechanical properties and the sensitivity ratios, the material constants of the soils and initial conditions of the ground were deduced first by simulating the laboratory tests through the SYS Cam-clay model mentioned above. The details of the constitutive model employed are described in the appendices and references. The constitutive model is capable of expressing the behaviour of a wide range of soils, ranging from naturally deposited clay (Nakano et al., 2005; Noda et al., 2005b) to sand (Asaoka et al., 2002; Asaoka, 2003) or intermediate soil (Nakano et al., 2008), within the same theoretical framework. Next, based on the information made available regarding the embankment's construction history, etc., soil-water coupled finite deformation analyses were performed under two-dimensional plane strain conditions. In the analyses, after simulating Stages 1 to 3 of the embankment loading history, rapid embankment loading was carried out to cause embankment and ground failure.

\section{INFORMATION PROVIDED REGARDING THE GROUND AND TEST EMBANKMENT FOR THE BLIND TEST}

In the blind test, the test embankment and ground conditions illustrated in Fig. 1 were made available with respect to an unknown embankment constructed on extremely soft ground at a specific location somewhere in

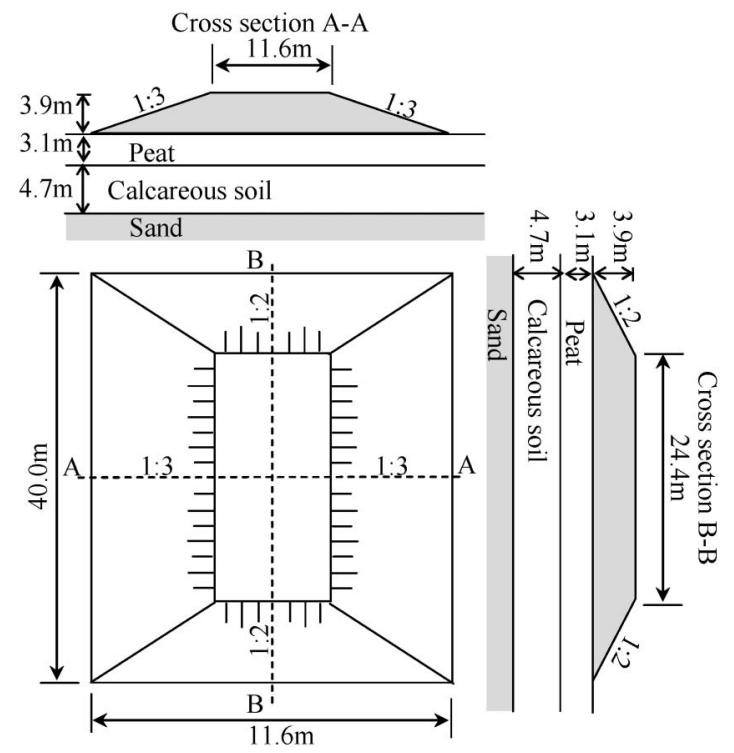

Fig. 1. External appearance of the test embankment

the world. The toe of slope of the embankment is $35.1 \mathrm{~m}$ $\times 40.0 \mathrm{~m}$, and the slope inclinations along cross sections A-A and B-B are 1:2 and 1:3, respectively. The ground is a so-called unusual soil ground, the top layer being a $3.1-\mathrm{m}$ peat layer and the layer beneath it being $4.7 \mathrm{~m}$ of calcareous soil. With respect to the ground structure at depths greater than $7.8 \mathrm{~m}$, the only information provided in the test, as can be seen from the figures and tables that follow, was that the soil material is sandy soil. Other data, such as the type of sand, soil conditions, and hydraulic conditions, were not made available.

As for information regarding the ground interior, the initial pore pressure distribution, consolidation pressure distribution (Fig. 2), physical properties of each ground layer (Table 1), and results of laboratory testing of the mechanical properties of each ground layer (Table 2, Figs. 3 and 4) were provided. Undrained triaxial tests were performed only at one depth each for the peat and calcareous soil layers. For the other tests, the peat layer was divided into two sublayers (Layers 1-2), and the calcareous soil layer was divided into 3 sublayers (Layers 3-5), after which each test was carried out with respect to each of the 5 layers. The coefficient of permeability $k_{0}$ with respect to the void ratio $e=e_{0}$ of the soils in-situ and the permeability coefficient variation rate $C$ in the logarithmic equation below were made available from the constant strain rate consolidation tests.

$$
e-e_{0}=C \ln \frac{k}{k_{0}}
$$

It can be seen from the given data that the ground is in a saturated state almost up to its surface and that it is a sensitive and soft ground with water contents of 100 to $340 \%$ and sensitivity ratios of 7 to 12 .

The information provided with respect to the test embankment was limited to (1) the embankment thicknesses in Stages 1 to 3 (see Fig. 5, Construction history), (2) the 


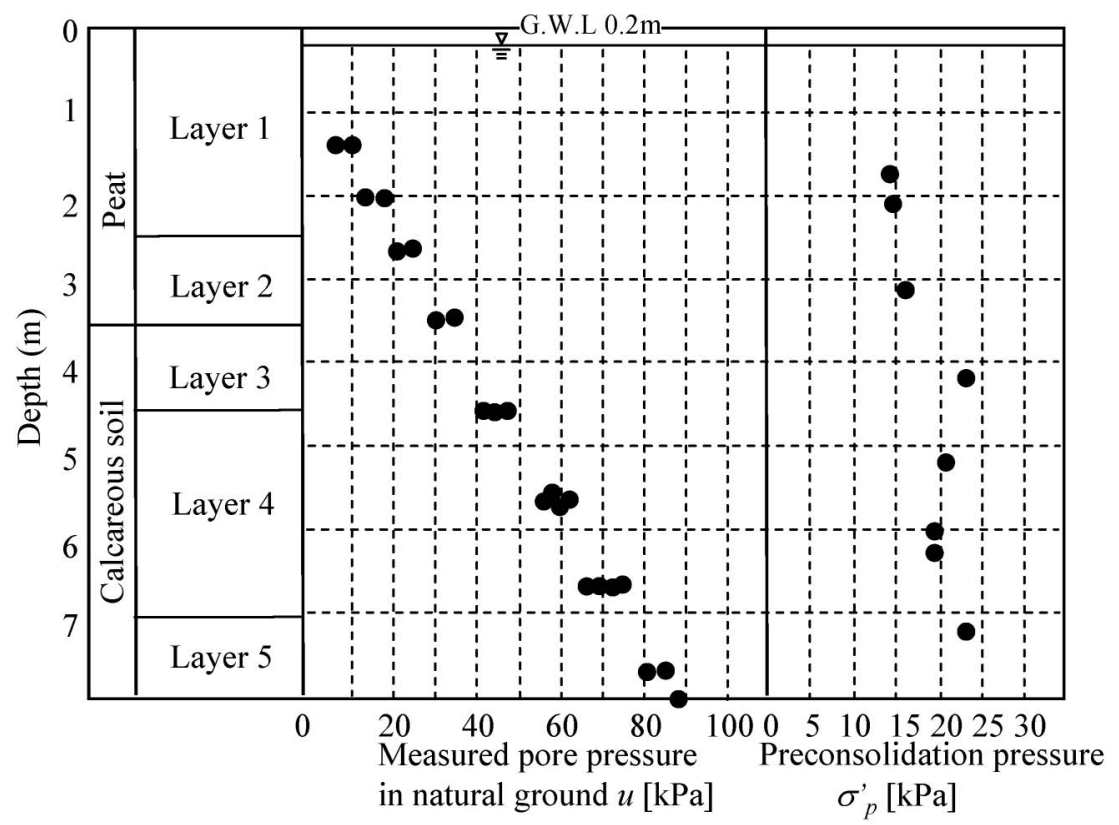

Fig. 2. Distributions of the initial pore pressures and preconsolidation pressures

Table 1. Results of mechanical tests for each soil layer of the ground

\begin{tabular}{|c|c|c|c|c|c|c|c|}
\hline & & $\begin{array}{l}\text { Layer thickness } \\
(\mathrm{m})\end{array}$ & $\begin{array}{l}\text { Soil density } \\
\rho_{\mathrm{s}}\left(\mathrm{t} / \mathrm{m}^{3}\right)\end{array}$ & $\begin{array}{l}\text { Wet unit weight } \\
\gamma_{\mathrm{t}}\left(\mathrm{kN} / \mathrm{m}^{3}\right)\end{array}$ & $\begin{array}{c}\text { Water content } \\
w(\%)\end{array}$ & $\begin{array}{c}\text { Void ratio } \\
e_{0}\end{array}$ & $\begin{array}{l}\text { Liquid limit } \\
\qquad w_{\mathrm{L}}(\%)\end{array}$ \\
\hline \multirow{2}{*}{ Peat } & Layer 1 & 2.5 & 1.78 & 10.89 & 341 & 6.07 & 313 \\
\hline & Layer 2 & 0.6 & 2.10 & 11.67 & 227 & 4.77 & 221 \\
\hline \multirow{3}{*}{$\begin{array}{l}\text { Calcareous } \\
\text { soil }\end{array}$} & Layer 3 & 1.4 & 2.24 & 12.85 & 134 & 3.00 & 129 \\
\hline & Layer 4 & 2.5 & 2.56 & 13.93 & 106 & 2.71 & 103 \\
\hline & Layer 5 & 0.8 & 2.60 & 13.05 & 148 & 3.85 & 138 \\
\hline
\end{tabular}

Table 2. Results of mechanical tests for each soil layer of the embankment

\begin{tabular}{|c|c|c|c|c|c|c|}
\hline & & \multirow{2}{*}{$\begin{array}{l}\text { Sensitivity } \\
\text { ratio } S t\end{array}$} & \multirow{2}{*}{$\begin{array}{l}\text { Undrained } \\
\text { triaxial test }\end{array}$} & \multirow{2}{*}{$\begin{array}{c}\text { Constant } \\
\text { strain rate } \\
\text { consolidation } \\
\text { test }\end{array}$} & \multicolumn{2}{|c|}{$\begin{array}{l}\text { Permeability by constant strain } \\
\text { rate consolidation test }\end{array}$} \\
\hline & & & & & $\begin{array}{c}\text { In-situ }\left(e=e_{0}\right) \\
\text { permeability } \\
k_{0}(\mathrm{~cm} / \mathrm{sec})\end{array}$ & $\begin{array}{c}\text { Permeability } \\
\text { variation ratio } \\
C\end{array}$ \\
\hline \multirow{2}{*}{ Peat } & Layer 1 & 7 & $\bigcirc$ & $\bigcirc$ & $1.7 \times 10^{-6}$ & 0.73 \\
\hline & Layer 2 & 12 & $x$ & $\bigcirc$ & $4.0 \times 10^{-7}$ & 0.84 \\
\hline \multirow{3}{*}{$\begin{array}{l}\text { Calcareous } \\
\text { soil }\end{array}$} & Layer 3 & 12 & $x$ & $\bigcirc$ & $4.0 \times 10^{-8}$ & 0.83 \\
\hline & Layer 4 & 9 & $\bigcirc$ & $\bigcirc$ & $8.3 \times 10^{-6}$ & 0.73 \\
\hline & Layer 5 & 11 & $\bigcirc$ & $\bigcirc$ & $1.6 \times 10^{-7}$ & 0.62 \\
\hline
\end{tabular}

$\bigcirc$ : Test carried out $\quad \times$ : Test not carried out

water contents and wet densities of the embankment material in Stages 1 to 3 (Table 3), and (3) the fact that the embankment material is a sandy soil. That is to say, data for the test embankment regarding the material characteristics such as permeability, the degree of compaction, the drainage conditions, etc., at each stage were not made available. With respect to Stage 4, no information regarding the embankment material was provided.
Apart from the data shown in Fig. 5, the authors were also notified that the loading rate in this stage, in which the embankment thickness was rapidly increased until failure occurred, was 1.0-1.2 m/day. However, other detailed information, such as the type of loading in Stage 4 whether it was repeated intermittent loading or gradually increasing loading, the manner in which the embankment was made to fail, etc., was not provided. 


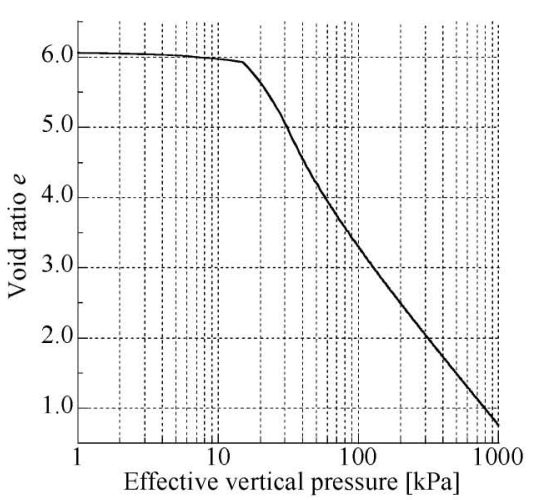

(a) Layer 1

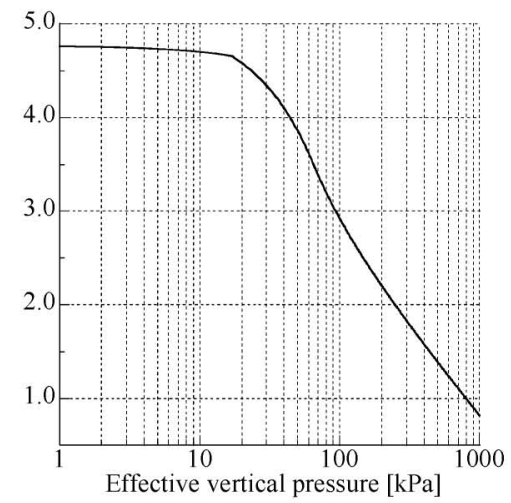

(b) Layer 2

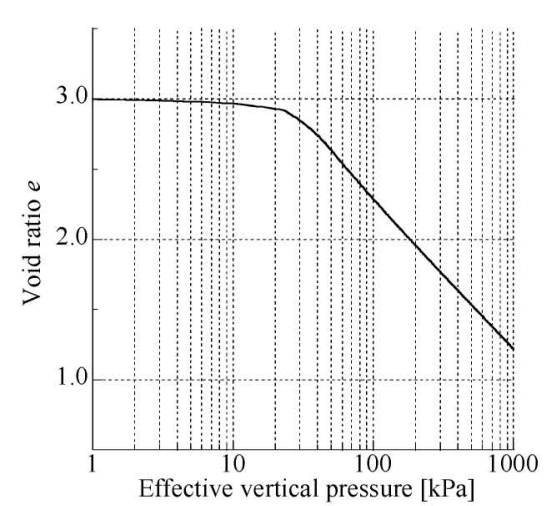

(c) Layer 3

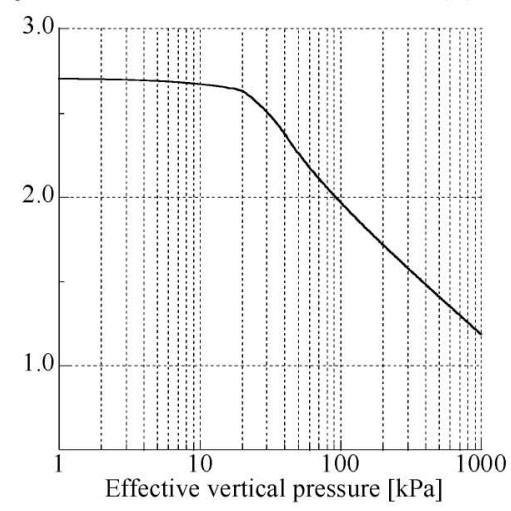

(d) Layer 4

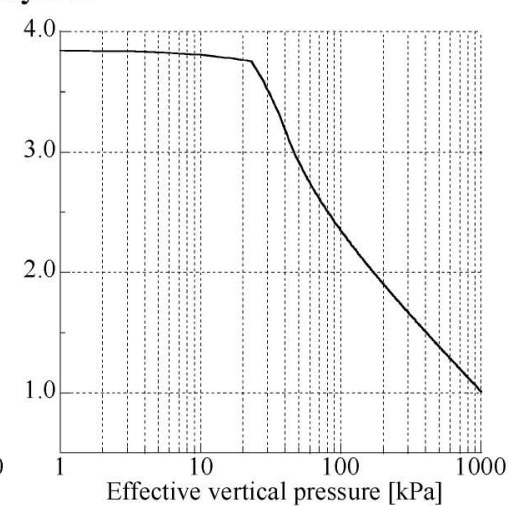

(e) Layer 5

Fig. 3. Relationships $\left(e \sim \log \sigma_{\mathrm{v}}\right)$ obtained through constant strain rate consolidation tests

The computations in this paper were carried out using the above information (Figs. 1 to 5 and Tables 1 to 3 ) provided by the organizers of the blind test together with data obtained by considering the constitutive model for soils (SYS Cam-clay model) in order to deduce other unprovided data that were required for performing the computations.

\section{COMPUTATION OF MATERIAL CONSTANTS AND IN-SITU INITIAL CONDITIONS}

In this study, the material constants and in-situ initial conditions of the ground were determined by simulating all the mechanical test results that had been made available through the response of the SYS Cam-clay model considering ideal sampling paths (Noda et al., 2005a; refer to APPENDIX A2 for details). The results of simulation of the laboratory tests with respect to Layers 1 to 5 are illustrated in Fig. 6 (1) to (5). The open circle in each figure indicates the in-situ initial condition. In the undrained triaxial test results (a), the stresses have been converted to show the $p^{\prime}-q$ relationship. The sensitivity ratios are compared in Table 4. All test results were well simulated by using the set of material constants and in-situ initial conditions for each layer.

Table 5 shows the material constants and in-situ initial conditions of the soils as determined by the method of computation described above. Since information regarding the compression curve NCL of the remolded samples was not made available in the blind test, the gradients $(\tilde{\lambda})$ were determined from the liquid limits using Skempton's equation (1944). In addition, the values of the intercepts (N) were determined by finding values that would simulate the sensitivity ratios. As for the other material constants, the respective values allotted to Layers 1 and 2 were basically the same based on the assumption that the two layers are made up of the same type of material (peat). Similarly, since Layers 3, 4, and 5 are made up of the same type of material (calcareous soil), the respective material constants allotted to these three layers were basically the same. However, as shown in Table 1, even though Layers 1 and 2 contain the same material, peat, there are differences between them, such as differences of, as much as $92 \%$ in their liquid limits and 1.3 in their void ratios. These characteristics were expressed by the differences in the indices of decay of structure and in the initial conditions.

Regarding the embankment, it is likely that its mechanical characteristics would be affected by a number of factors including its partial saturation condition and hardness. Since the information provided in the blind test was not sufficient, the embankment was assumed to consist of saturated elasto-plastic sandy soil. Based on this assumption, the material constants and initial conditions were allotted as shown in Table 5 (Noda et al., 2009).

Figure 7 illustrates the distribution of the initial values of the ground in the direction of depth. It was assumed that the specific volume, degree of structure, degree of 


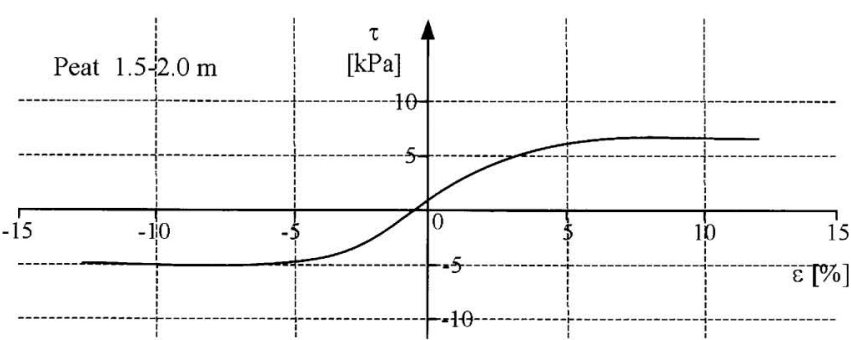

(a) Layer 1

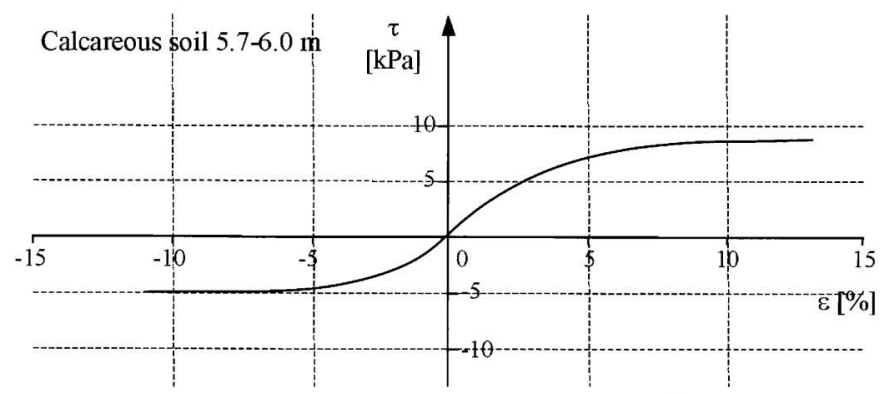

(b) Layer 4
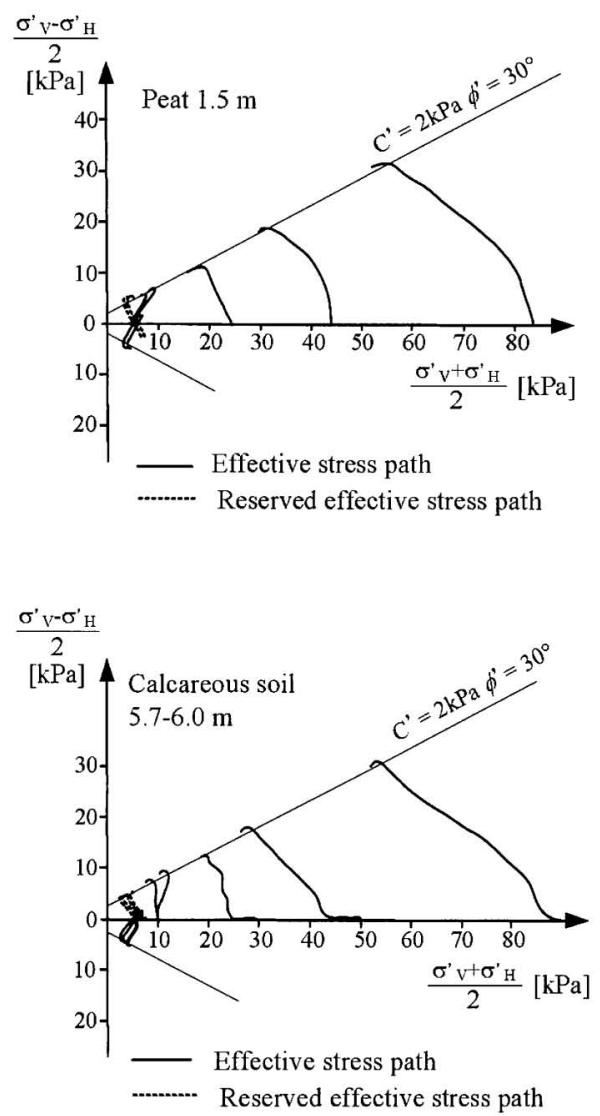

Fig. 4. Results of undrained triaxial tests

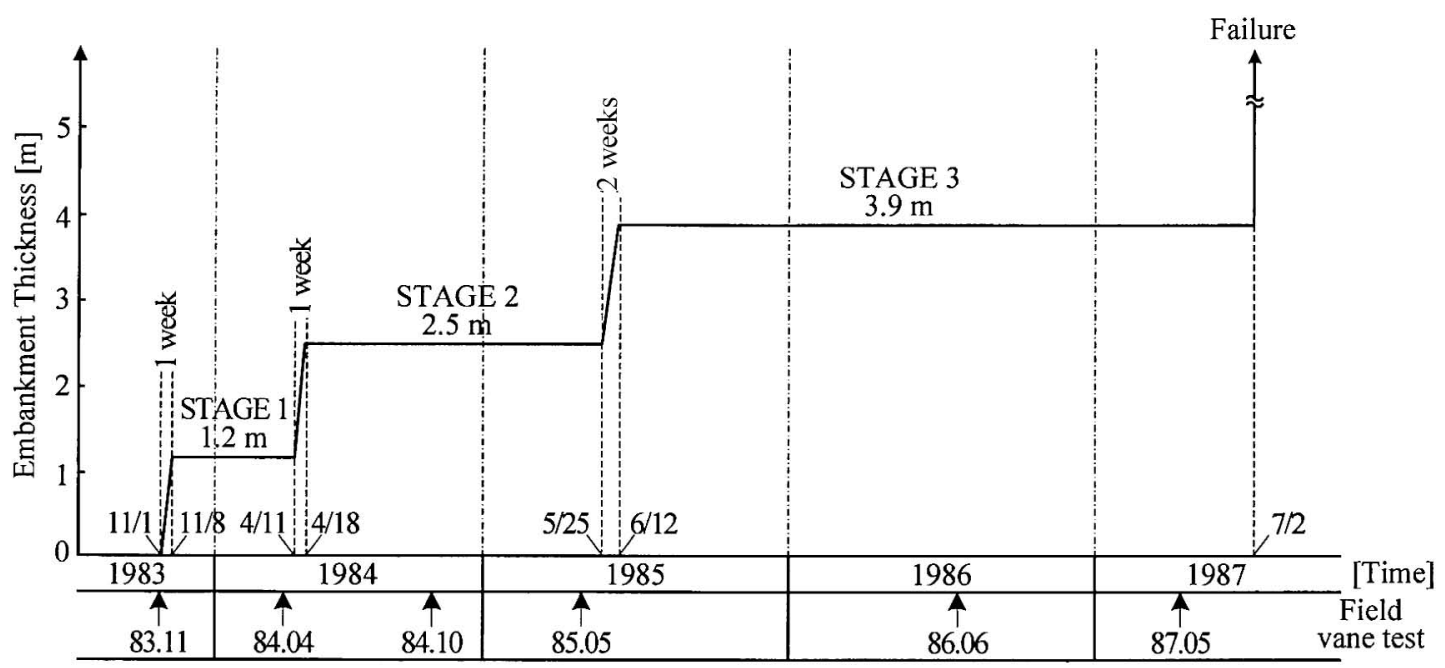

Fig. 5. Construction history of the test embankment

Table 3. Material characteristics of the embankment

\begin{tabular}{c|c|c}
\hline Stage & Water content $w(\%)$ & Wet density $\rho_{\mathrm{t}}\left(\mathrm{t} / \mathrm{m}^{3}\right)$ \\
\hline 1 & 10.6 & 1.68 \\
\hline 2 & 8.0 & 1.76 \\
\hline 3 & 8.5 & 1.85 \\
\hline
\end{tabular}

anisotropy, and stress ratio were homogeneous in the direction of depth in each layer according to the values set out in Table 5. The overconsolidation ratio was distributed in proportion to the overburden pressure, taking into account the effect of gravity. Layer 4 has the smallest specific volume, but its consolidation yield stress and sensitivity ratio are small compared with those of the sur- 

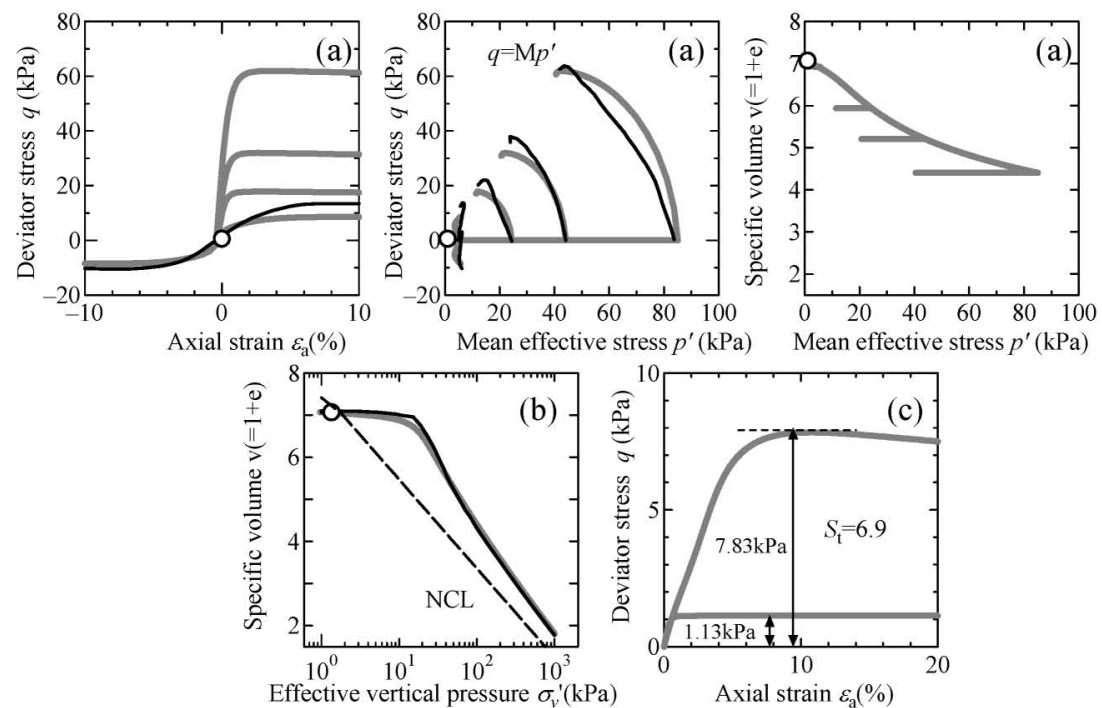

(1) Layer 1

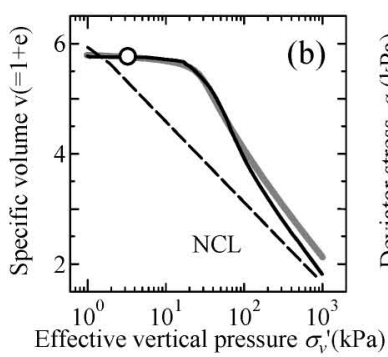

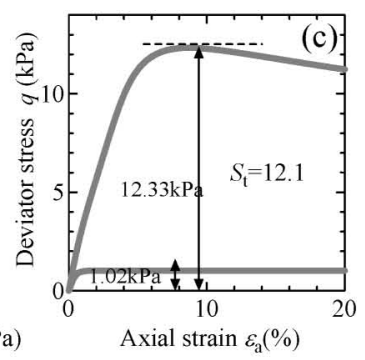

(2) Layer 2

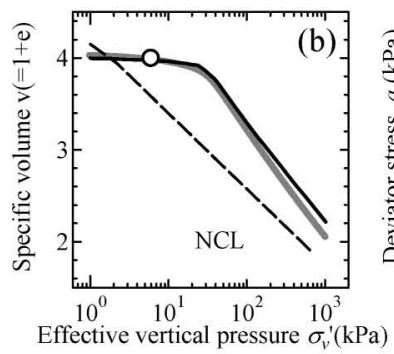

(3) Layer 3

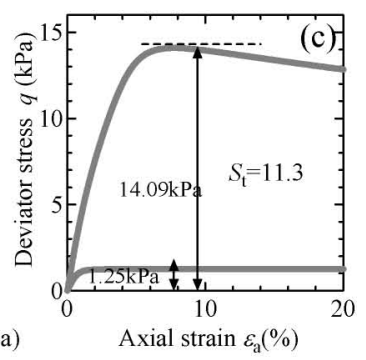

Axial strain $\varepsilon_{\mathrm{a}}(\%)$
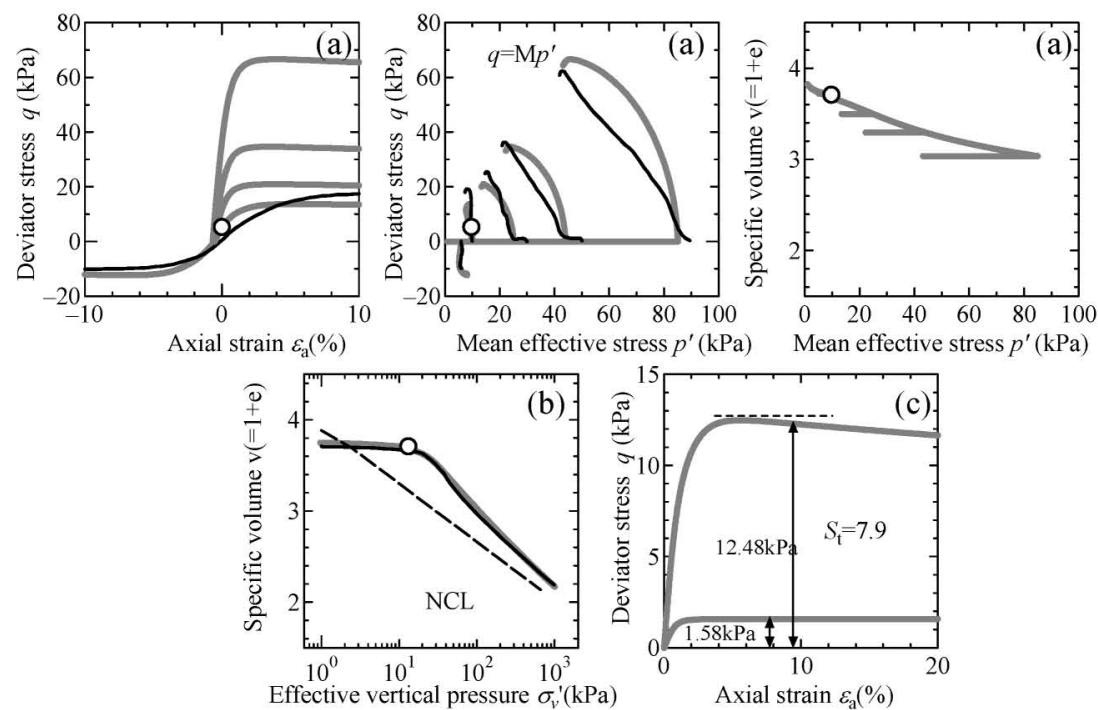

(4) Layer 4
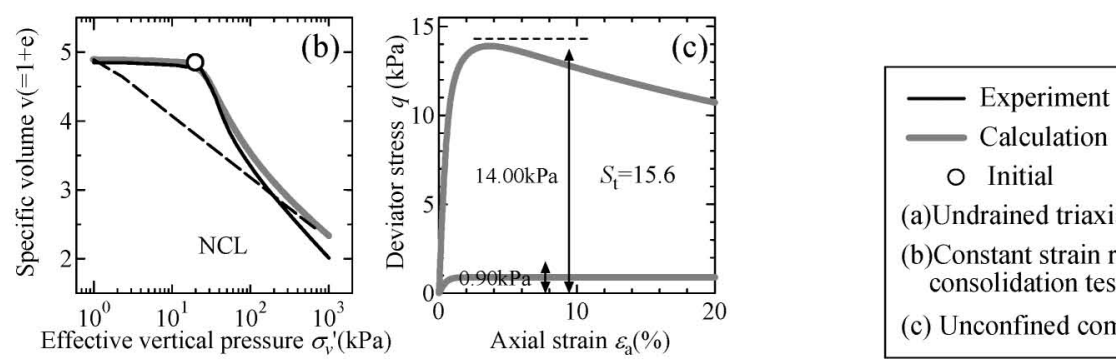

Initial

(a)Undrained triaxial test

(b)Constant strain rate

consolidation test

(c) Unconfined compression test

(5) Layer 5

Fig. 6. Results of simulation using the SYS Cam-clay model 
rounding soils. Because of this, it can be observed that its degree of structure and overconsolidation ratio are both low.

\section{CONDITIONS OF COMPUTATION}

In the computations, the entire cross section A-A (inclination of embankment slope $=1: 3$ ) was modelled under 2-dimensional plane strain conditions using the finite element mesh shown in Fig. 8. A sufficiently large width, $110 \mathrm{~m}$, was used for the analysis in the horizontal direction so that the effect of embankment loading would not

Table 4. Sensitivity ratios

\begin{tabular}{c|c|c}
\hline & Experiment & Model response \\
\hline Layer 1 & 7 & 6.9 \\
\hline Layer 2 & 12 & 12.1 \\
\hline Layer 3 & 12 & 11.3 \\
\hline Layer 4 & 9 & 7.9 \\
\hline Layer 5 & 11 & 15.6 \\
\hline
\end{tabular}

appear at the boundaries. The depth considered for the analysis in the vertical direction was $7.8 \mathrm{~m}$, which is the given cumulative depth of Layers 1 to 5 in the test. Cross section A-A is closer to the plane strain conditions than $\mathrm{B}-\mathrm{B}$. The reason for choosing the former as the cross section for the current analysis was that the organizers of the blind test had stipulated that the settlement profile of this cross section be submitted. The upper end of the ground (ground surface) was taken as the hydraulic boundary and was made to coincide with the water level by making the water pressure always zero. By assuming a soil layer with high permeability to exist below it, the bottom surface of the ground was taken to be the permeable boundary while the initial head condition (water pressure) remains unchanged. The lateral faces were made to be impermeable boundaries.

In order to carry out embankment loading, finite elements representing the embankment were added to the ground illustrated by the mesh diagram in Fig. 8 stage by stage. At each stage, the finite element mesh was added up to the height specified for that stage in the construction history of the test embankment shown in Fig. 2. The method of embankment loading (finite element addition)

Table 5. Computed material constants for each layer and in-situ initial conditions

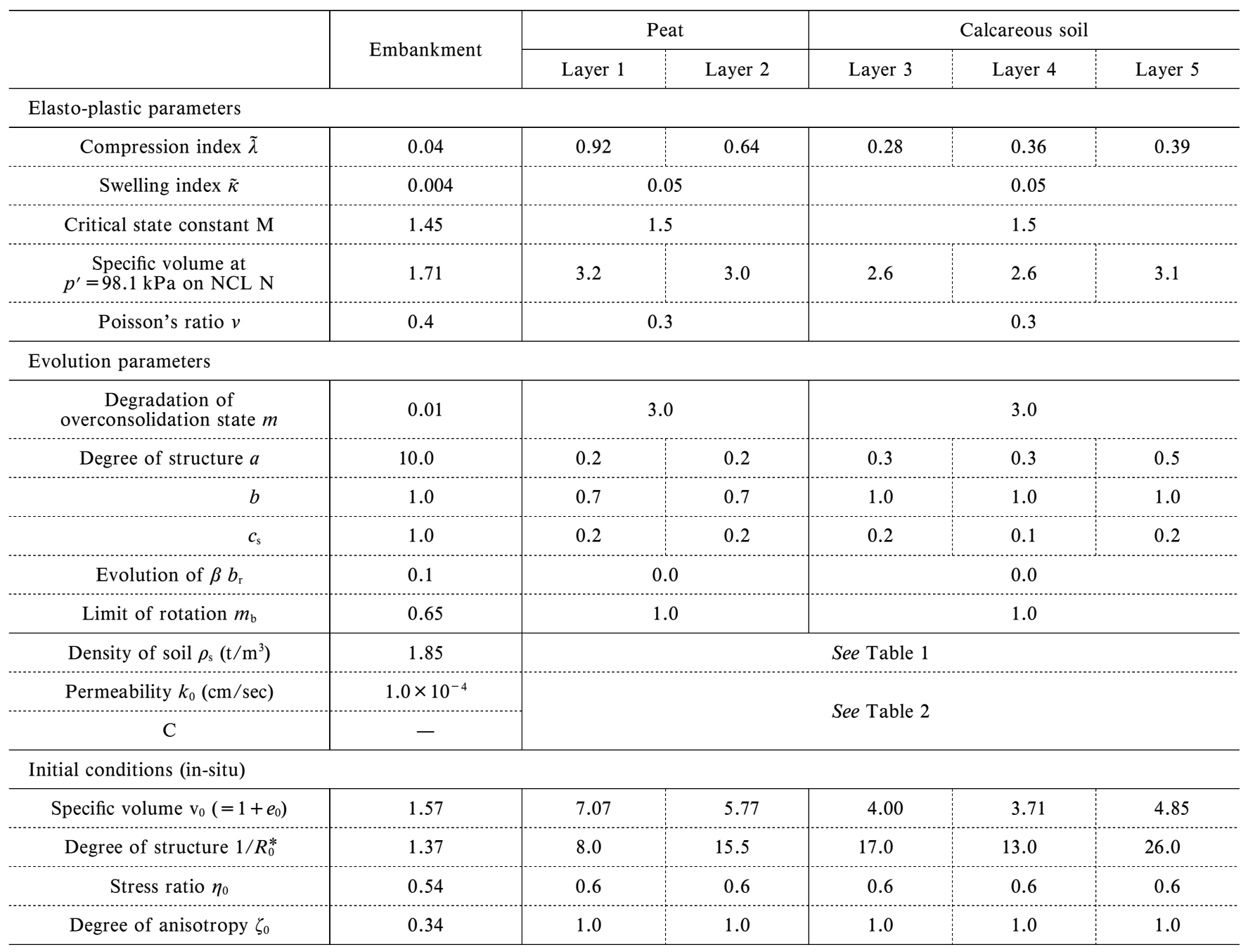




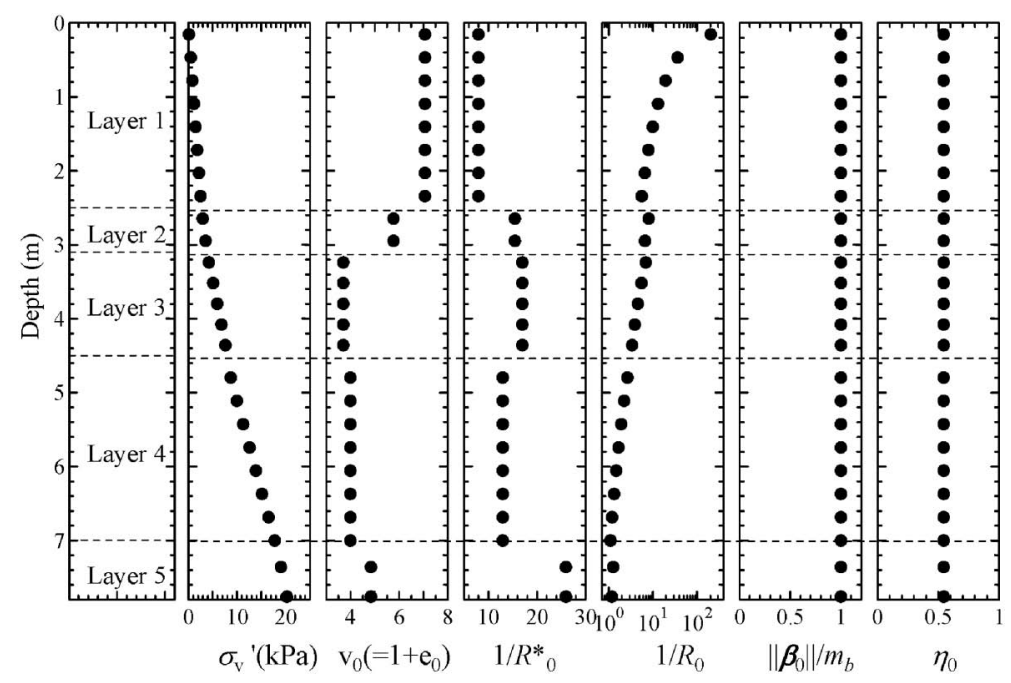

Fig. 7. Distributions of the initial values of foundation

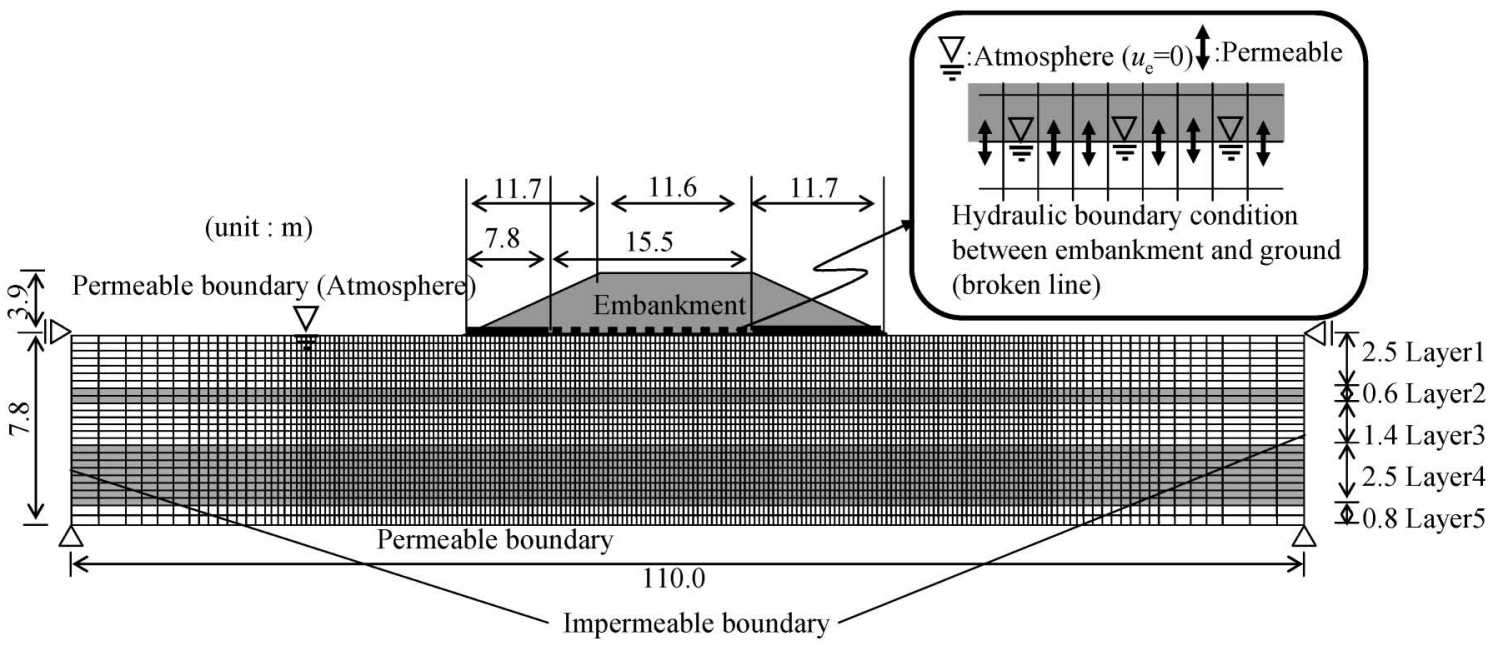

Fig. 8. Finite element mesh and boundary conditions

is described in detail in APPENDIX A3.

In the computations, the embankment loading was executed taking account of the ground surface profile at each stage of loading, with the finite elements being increased stepwise during embankment construction so that the specified "Embankment Thickness" for each stage (Fig. 5) was attained at the center of the embankment. For all stages from Stage 1 up to 4 , the computations were performed with the slope inclination of $1: 3$ being maintained while creating the finite elements. In the case of the computations for Stage 4 where the loading is rapid, however, the density of the soil particles was set to a high value, $5.2 \mathrm{t} / \mathrm{m}^{3}$, in advance. This was done because there was a risk of profile-related problems such as the embankment's crown width becoming too narrow or reaching zero during loading.

Since hardly any information had been provided in the blind test regarding the hydraulic boundary (boundary conditions, boundary state) between the embankment and the ground, it was assumed that a sand mat, i.e., a drainage layer, existed between them. An actual ground inevitably possesses some sort of "initial irregularity" such as ground non-uniformity, including non-uniform permeability, asymmetrical loading history, etc. Because of this, we can envision that symmetry in deformation of the ground and embankment would be lost. For the sake of simplicity, initial irregularity was allotted only to the undrained state of the bottom part of the embankment. Specifically, a width of $7.8 \mathrm{~m}$ from the left-hand side toe of slope and a width of $11.7 \mathrm{~m}$ from the right-hand side toe of slope at the embankment's base were set to be under atmospheric pressure (water pressure $=0$ ). In the remaining part of the $35-\mathrm{m}$ total base width, one of the three finite elements was set to be under atmospheric pressure, while the other two were rendered capable of exchanging water with the elements lying above and below them (see Fig. 8). On the basis of surface area, approximately $70 \%$ of the total base area of the embankment was under atmospheric pressure. 


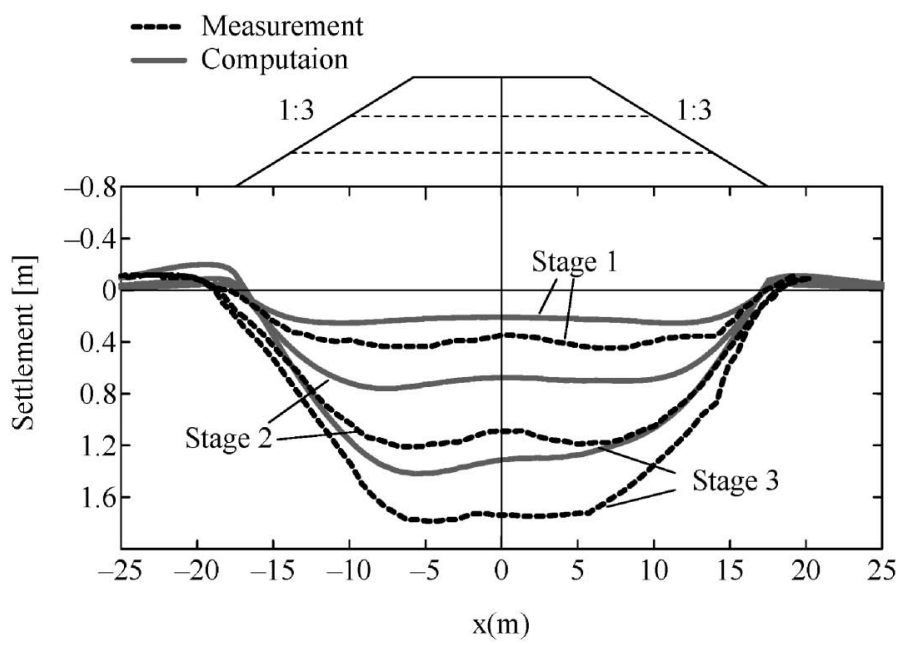

Fig. 9. Settlement profiles of ground surface at the end of each stage

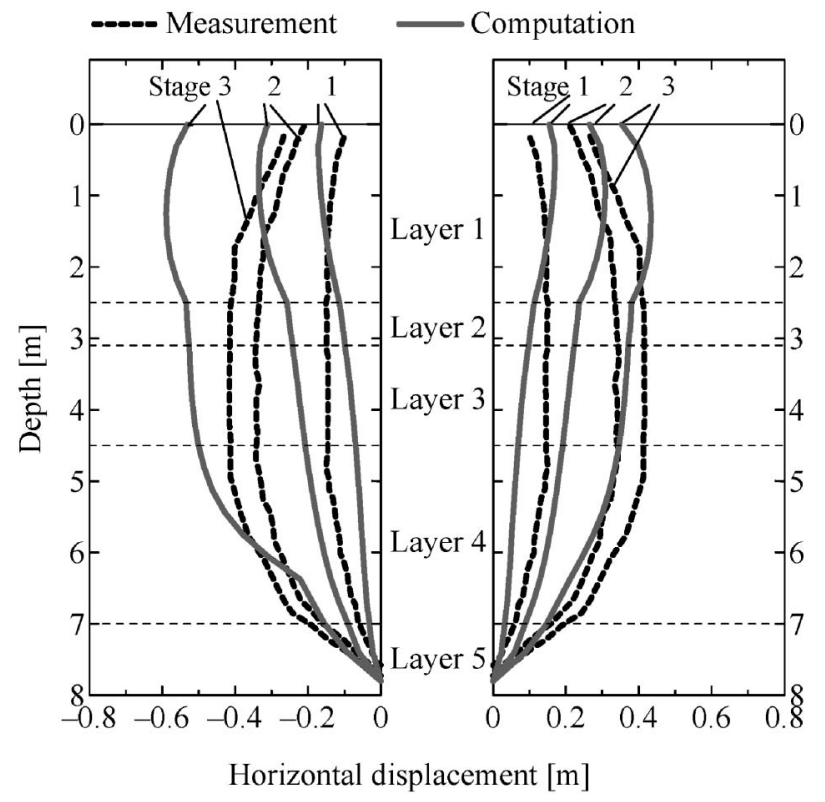

Fig. 10. Lateral displacement profiles at the end of each stage

\section{RESULTS OF THE COMPUTATIONS}

The numerical calculations in this work were performed using the analysis tool GEOASIA, which is capable of handling all behaviour from deformation up to failure in an integrated manner. To facilitate understanding, the computed results pertaining to the deformation behaviour at each stage of loading (Stages 1 to 3 ) before failure and those pertaining to failure due to rapid loading (Stage 4) are described below separately.

\section{Stage 1 to Stage 3}

The computed results are compared with the results of actual measurements first. The settlement profiles of the ground and the lateral displacements at the end of each stage in the cross sections of both slope toes are shown in Figs. 9 and 10, respectively. Figure 11 shows the varia-

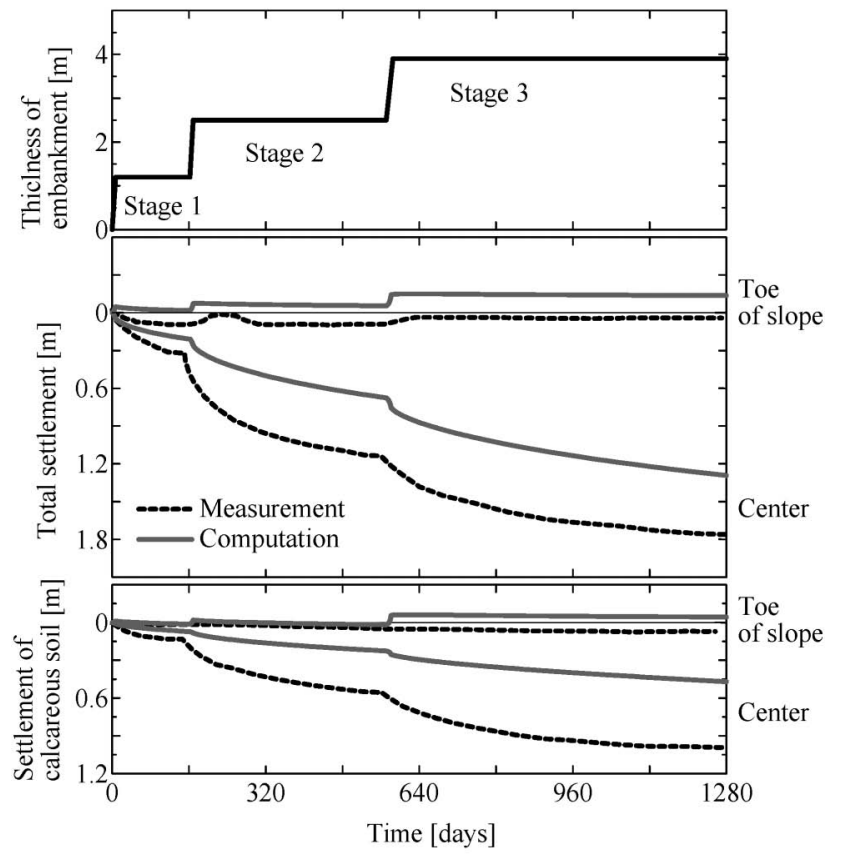

---- Measurement Computation

Fig. 11. Temporal variations of total settlement and of settlement of calcareous soil at the center and toe of slope of the embankment

tions in the total settlement and in the settlement of the calcareous soil at the embankment's center and toe of the slope with elapsed time. In the above three figures, the dark dashed lines indicate actual measurements, and the grey lines indicate the computed results. With respect to Fig. 10, actual lateral displacement measurement data were available only for the right-hand side (the side that exhibited slippage in Stage 4). Therefore, the data for the right-hand side was also used for the left-hand side.

The computed ground surface settlement profiles at the end of each stage are of the W type. They show good agreement with the measured profiles. In the case of lateral displacement, it is known that there is often a gap be- 
tween the values predicted by numerical calculations and actual values (Takeuchi et al., 2006; Nakai, 2002). In the current case, however, one could say that there is com-

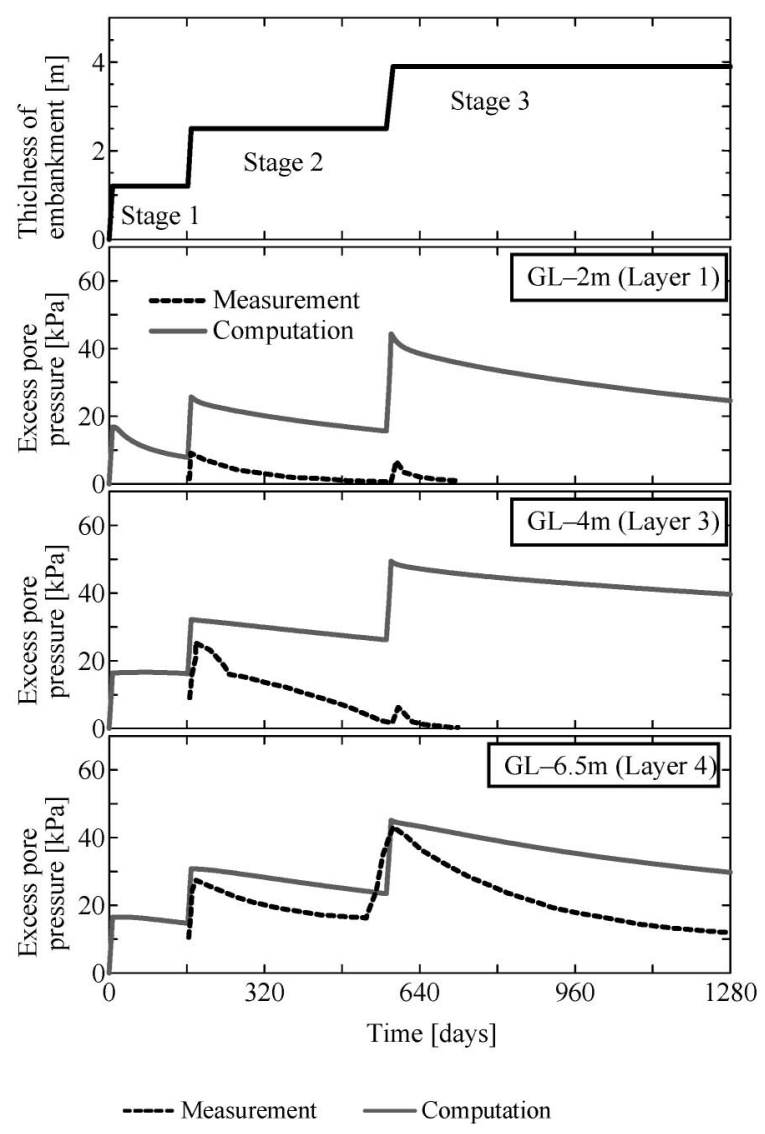

Fig. 12. Temporal variations of excess pore pressure immediately below the center of the embankment paratively good agreement.

With respect to the variation of settlement with time, however, the difference in the calculated and measured settlements of the calcareous layer was reflected in the total settlement. For example, the computed total settlement of the embankment center at the end of Stage 3 was about $30 \%$ smaller than the actual value. Figure 12 illustrates the variations with time of the excess pore pressures in the ground directly below the center of the embankment. In the deeper part of the ground (Layer 4), there is comparatively good agreement between the computed and measured values, although the computed pressure dissipation is somewhat slower than the measured pressure dissipation. On the other hand, in the shallow (Layer 1) and central parts (Layer 3), the calculated excess pore pressures arising during loading are higher compared with the measured results. Moreover, the pressure dissipation after loading has ended is also slower. The reason for these discrepancies is believed to lie in the fact that the permeabilities allotted in the analysis to the embankmentground system were lower than the actual ones, particularly near the boundary between the embankment and the ground.

Furthermore, Layers 1 to 5 are all prone to disturbance because their sensitivity ratios are comparatively high. This means that the actual disturbance in the soils may have been at levels that cannot be explained by the ideal sampling path (from sampling up to test commencement) considered in the current analysis, and as a result, there is a possibility that the estimated compressibilities of the soils in-situ were too low.

From the above comparison of the computed and measured results, it can be understood that when carrying out an analysis to predict deformation behaviour using

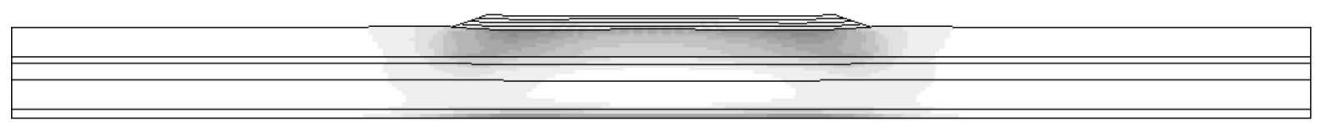

(1) At the end of Stage 1

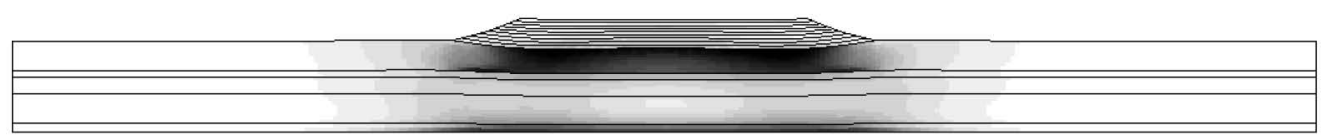

(2) At the end of Stage 2

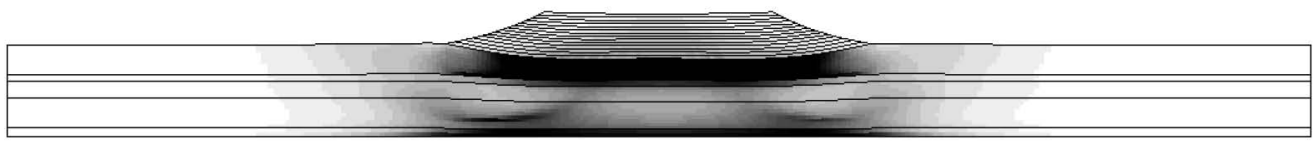

(3) At the end of Stage 3

Fig. 13. Shear strain distributions at the end of each stage 


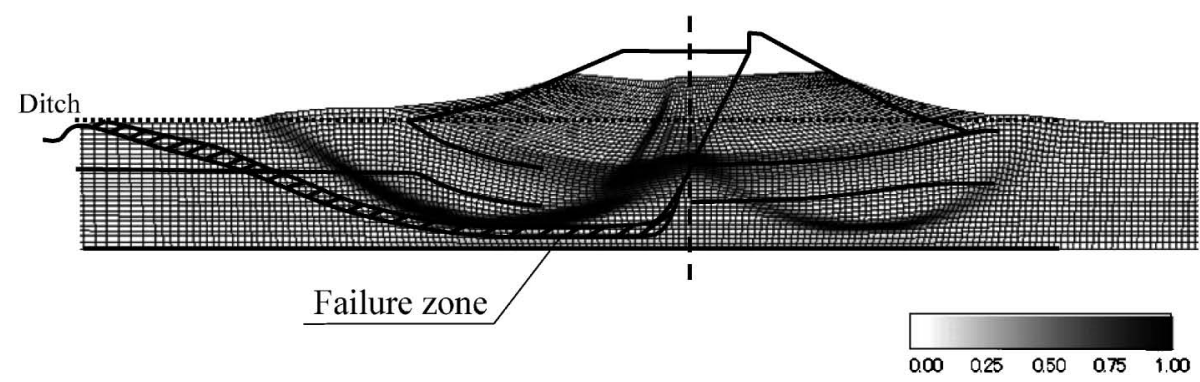

Fig. 14. Shear strain distribution at the time of failure (with an enlarged view of the embankment) Solid line: Observation

only ground information obtained in advance, it is important that the permeabilities of the embankmentground system as a whole and the loading history be simulated correctly. It is also important to determine the initial in-situ conditions by simulating the laboratory mechanical test results of undisturbed samples with lower levels of disturbance in consideration of the soil disturbance that occurred from the time of soil sampling to setting in the apparatus.

Figure 13 illustrates the shear strain $\varepsilon_{\mathrm{s}}$ distributions at the end of each loading stage (the dark lines denote the interlayer boundaries). Here, $\varepsilon_{\mathrm{s}}$ is defined through the following equations using the deformation gradient tensor $\boldsymbol{F}$ and the identity tensor $I: \varepsilon_{\mathrm{s}}=\sqrt{2 / 3 e^{\prime} \cdot e^{\prime}}, e^{\prime}=e-1 / 3 \mathrm{tr}$ $(e) I, e=2 / 1\left\{\boldsymbol{I}-\left(\boldsymbol{F} \boldsymbol{F}^{T}\right)^{-1}\right\}$. In Stage 3, slip lines have begun to appear in Layer 4.

\section{Deformation and Failure Behaviour in Stage 4}

In the case of the actual test embankment, failure occurred during rapid loading when the embankment height reached $4.05 \mathrm{~m}$, while the computed results converted for the same unit weight predicted failure to occur at $4.6 \mathrm{~m}$. Figure 14 shows the shear strain distributions at the time of failure. The lines within the figure are slip lines, which were deduced from observations of the test embankment. Slip surfaces can be observed passing through the embankment where the shear strains are localized, and, in the deeper parts of the ground, there is good coincidence with the actual slip profiles. It is believed that the slip surfaces were induced towards the left-hand side because of the existence of the ditch shown on the left side of the figure in the actual ground.

The behaviours of the elements denoted by points $\mathrm{A}$, B, C, D, and E in Fig. 15 are illustrated in Figs. 16 and 17. The start and end of loading at each stage are also shown within these figures. It can be observed that all elements repeatedly exhibit shear behaviour in a nearly undrained state during loading and one-dimensional consolidation behaviour during the periods (constant embankment height periods) intervening the embankment loading stages.

Next, we look at element D in Layer 4, where slip failure occurred (Fig. 16). Although the specific volume of Layer 4 is small compared with the other layers, its consolidation yield stress and sensitivity ratio are also small. Consequently, its degree of structure and overcon-

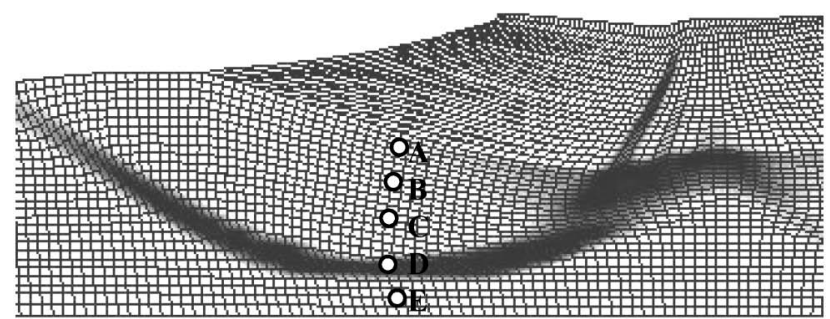

Fig. 15. Locations of the elements (A, B, C, D, E: Layers 1-5, respectively)

solidation ratio are also low. Because of this, overconsolidation is almost completely lost during loading in Stage 3, and the stress ratio increases up to the vicinity of the critical state line, resulting in commencement of softening with plastic compression. This changes to temporary hardening during the constant embankment height periods steps in Stage 3. In Stage 4, however, rapid softening begins again, and large shearing due to acute decay of structure occurs, with the soil remaining in the nearly undrained state (constant volume).

In contrast, although the specific volumes of Layers 2 and 3 are large compared with Layer 4, their consolidation yield stresses and sensitivity ratios are also large. Consequently, the overconsolidation ratios are large, and no softening takes place because decay of structure does not occur easily. In the case of Layers 1 and 5, which are close to the drainage layers, the elements, as a whole, exhibit one-dimensional consolidation behaviour, and their stress ratios do not become appreciably large.

\section{CONCLUSIONS}

This paper describes the results of analyses carried out in a blind test planned at the Earth Forum held at the Kyodai-Kaikan, Kyoto University, on November 18, 2006 in memory of Professor Toru Shibata. The task of the test was prediction of the deformation and failure behaviours of a test embankment constructed in several stages in Poland in 1983 on a soft ground made up of peat and calcareous clay, using limited data made available regarding the type of soils and boundary conditions. The authors utilized the analysis tool GEOASIA, which is capable of handling soil behaviour problems without differentiating between the phenomena of deformation 

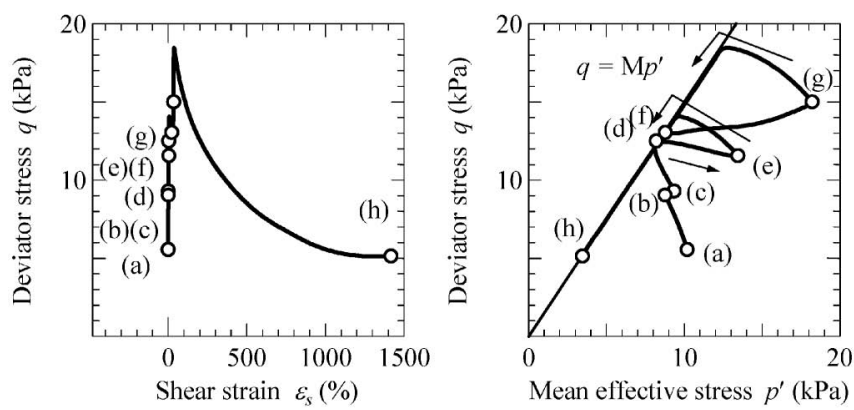

(a) Start of loading (Stage 1)

(b) End of loading (Stage 1)

(c) Start of loading (Stage 2)

(d) End of loading (Stage 2)

(e) Start of loading (Stage 2)

(f) End of loading (Stage 3)

(g) Start of loading (Stage 4)

(h) Failure
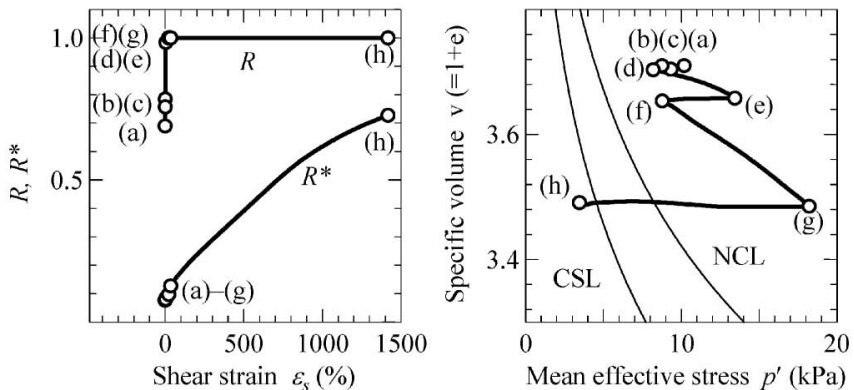

Fig. 16. Behavior of element D (Layer 4)

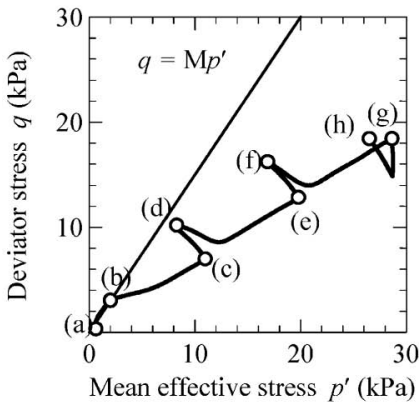

(1) Element A (Layer 1)

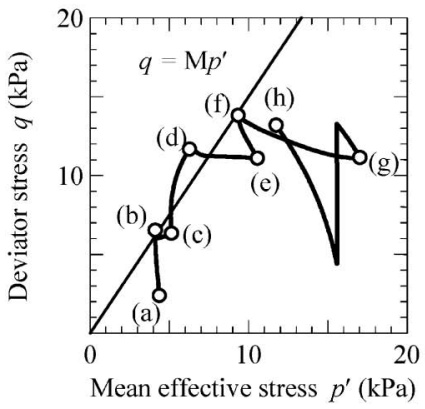

(3) Element C (Layer 3)

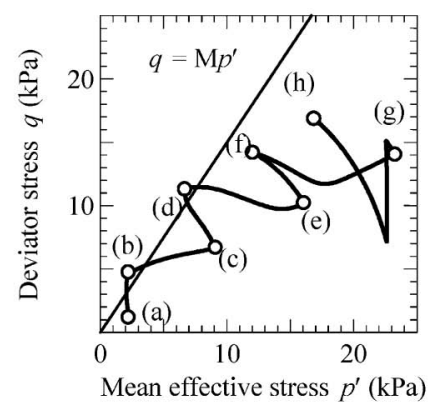

(2) Element B (Layer 2)

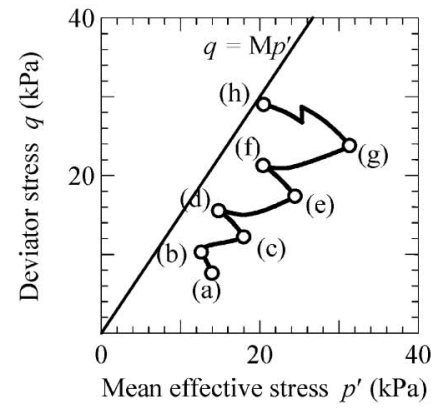

(4) Element E (Layer 5)

Fig. 17. Stress paths of elements A (Layer 1), B (Layer 2), C (Layer 3), and E (Layer 5)

and failure, to carry out computations in order to predict the behaviour of the embankment-ground system continuously from deformation up to failure. The material constants and ground conditions, were calculated from laboratory test results including sensitivity ratios, and used in the analysis without making any modifications based on prior experience.

Although sufficient information regarding the material characteristics of the embankment, its permeability, etc. were not made available in advance, the $\mathrm{W}$-type ground settlement and slip surface profiles passing through the embankment predicted through the computations showed good agreement with the respective measured profiles. The computed results converted for the same unit weight predicted failure to occur at an embankment height of $4.6 \mathrm{~m}$. This is in near agreement with the behaviour of the actual test embankment, which failed at a height of $4.05 \mathrm{~m}$. In addition, the predictions for the lateral displacements also agreed fairly well with the actual measurements. 
The results of the current analysis indicated that the cause of the slip failure was Layer 4, which was made up of calcareous soil. Although this layer has the smallest specific volume (high density), its consolidation yield stress and sensitivity ratio are also small. Its behaviour can be explained as outlined below by the elasto-plastic model (SYS Cam-clay model) that describes the action of the soil skeleton structure. Because of undrained-type shear during loading, the stress ratio increases up to the vicinity of the critical state line faster in Layer 4, in which both the level of structure and overconsolidation are low, compared with the other layers. This is followed by rapid softening along with decay of structure. As explained above, soil strength is determined not only by soil density, but also by the action of the soil skeleton structure acquired by the soil during its deposition. Therefore, in prediction of ground deformation and failure, it is extremely important to deduce the amount of skeleton structure possessed by the soil in-situ and the manner in which changes occur due to plastic deformation. In addition, information from laboratory mechanical tests using undisturbed samples, such as sensitivity ratios, is essential in order to deduce these values.

\section{APPENDIX 1: THE SUPER/SUBLOADING YIELD SURFACE (SYS) CAM-CLAY MODEL}

The Quantified Expression of Structure, Overconsolidation, Anisotropy, and Their Respective Evolution Rules

Naturally deposited soils, whether clayey or sandy, generally exist in a 'structured' and overconsolidated state. To describe the deformation behaviour of a soil in this state, we have to start from the base of an elasto-plastic model of a de-structured soil in a state of normal consolidation. Given that a soil in this unstructured and normally consolidated state still possesses anisotropy, we take for our 'base' in this paper the corrected Cam-clay model of Roscoe and Burland (1968) with the introduced addition of the rotational hardening concept of Sekiguchi and Ohta (1977), which treats stress parameter $\eta^{*}$ and its evolution rule as an expression of anisotropy. The degrees of structure and overconsolidation are then introduced and quantified by means of the two concepts of the superloading surface for structure (Asaoka et al., 1998a, 2000, 2002), and the subloading surface for overconsolidation (Hashiguchi, 1978, 1989; Asaoka et al., 1997). That is to say, the degree of structure is expressed by means of a superloading surface situated on the outside of the Cam-clay normal-yield surface and similar to it (the center of similarity being the origin $p^{\prime}=q=0$ and the similarity rate being given by $R^{*}\left(0<R^{*} \leq 1\right)$, while the overconsolidation state is expressed by means of a subloading surface situated on the inside of the superloading surface and again similar to it (center of similarity $p^{\prime}=q=0$, similarity rate $R(0<R \leq 1)$; reciprocal $1 / R$ is the overconsolidation ratio). $p^{\prime}$ here is the mean effective stress and $q$ is the shear stress. Using effective stress tensor $\boldsymbol{T}^{\prime}$ (tension: positive), we can say: $p^{\prime}=-\operatorname{tr} \boldsymbol{T}^{\prime} / 3$,

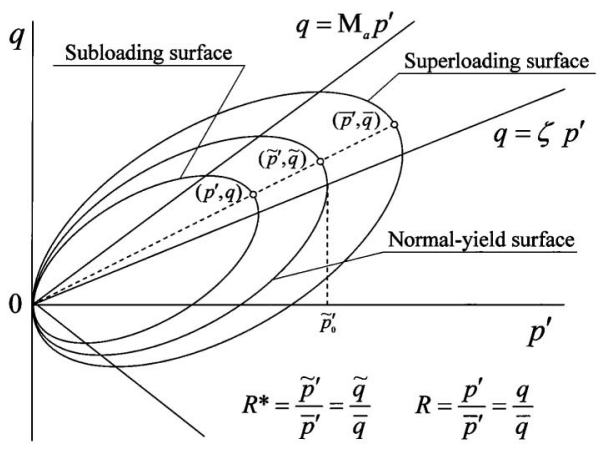

Fig. A1-1. Three loading surfaces

$q=\sqrt{3 / 2 S \cdot S}$.

The closer $R^{*}$ is to 0 the higher the degree of structure, but with the loss of structure that accompanies progressive plastic deformation $R^{*}$ will approach 1 (evolution rule for $R^{*}$ ). Similarly, the closer $R$ is to 0 the more overconsolidated the state of the soil, but as $R$ increases toward 1 with plastic deformation, the state of the soil will also approach normal consolidation (evolution rule for $R$ ). It can thus be assumed that the loss of structure with progressive plastic deformation brings a simultaneous release from overconsolidation (a transition to the normally consolidated state), resulting finally in conditions that match those in the Cam-clay model. The relative positions of the three loading surfaces, assuming conditions of axial symmetry, are as shown in Fig. A1-1.

If we start from Cam-clay Eq. (A1-1) below as our base, given that the current effective stress exists on the subloading surface, we first need to adapt relations to the subloading surface through the application of various elasto-plastic principles such as the associated flow rule and Prager's consistency condition, so as to give Eq. (A1-2).

The Cam-clay potential:

$$
\begin{gathered}
\mathrm{MD} \ln \frac{\tilde{p}^{\prime}}{\tilde{p}_{0}^{\prime}}+\mathrm{MD} \ln \frac{\mathrm{M}^{2}+\eta^{* 2}}{\mathrm{M}^{2}}+\int_{0}^{t} J \operatorname{tr} \boldsymbol{D}^{p} d \tau \\
=f\left(\tilde{p}^{\prime}, \eta^{*}\right)+\int_{0}^{t} J \operatorname{tr} \boldsymbol{D}^{p} d \tau=0
\end{gathered}
$$

The subloading surface:

$$
f\left(\tilde{p}^{\prime}, \eta^{*}\right)+\mathrm{MD} \ln R^{*}-\mathrm{MD} \ln R+\int_{0}^{t} J \operatorname{tr} D^{p} d \tau=0
$$

Here, $\mathrm{D}=(\tilde{\lambda}-\tilde{\kappa}) / \mathrm{M} /\left(1+e_{0}\right)$ is the dilatancy coefficient, and $\mathrm{M}, \tilde{\lambda}, \tilde{\kappa}$ and $e_{0}$ are the critical state constant, compression index, swelling index, and initial void ratio. $J=$ $(1+e) /\left(1+e_{0}\right)(e$ is the void ratio at time $t=t)$.

$-\int_{0}^{t} J \operatorname{tr} D^{p} d \tau$ (compression: positive) corresponds to the plastic volumetric strain $\eta^{*}$, the expression of anisotropy, is obtained using the rotational hardening variable $\boldsymbol{\beta}$, from the calculation $\eta^{*}=\sqrt{3 / 2 \hat{\boldsymbol{\eta}} \cdot \hat{\boldsymbol{\eta}}}, \hat{\boldsymbol{\eta}}=\boldsymbol{\eta}-\boldsymbol{\beta}$, $\boldsymbol{\eta}=\boldsymbol{S} / p^{\prime}, \quad \boldsymbol{S}=\boldsymbol{T}^{\prime}+p^{\prime} \boldsymbol{I} . \quad \boldsymbol{\beta}=\mathbf{0}$ expresses a state of no anisotropy. In the present paper, the evolution rules for $R^{*}, R$ and $\beta$ are given by the following equations: 
Evolution rule for $R^{*}$ :

$$
\begin{aligned}
& \dot{R}^{*}=J U^{*}\left\{c_{\mathrm{s}} \sqrt{2 / 3}\left\|D_{\mathrm{s}}^{p}\right\|+\left(1-c_{\mathrm{s}}\right)\left(-D_{\mathrm{v}}^{p}\right)\right\}, \\
& U^{*}=\frac{a}{\mathrm{D}} R^{* b}\left(1-R^{*}\right)^{c}
\end{aligned}
$$

Evolution rule for $R$ :

$$
\dot{R}=J U\left\|D^{p}\right\|, \quad U=-\frac{m}{\mathrm{D}} \ln R
$$

Evolution rule for $\boldsymbol{\beta}$ :

$$
\stackrel{\boldsymbol{\beta}}{=}=J \frac{b r}{\mathrm{D}} \sqrt{\frac{2}{3}}\left\|\boldsymbol{D}_{\mathrm{s}}^{p}\right\|\|\hat{\boldsymbol{\eta}}\|\left(m_{\mathrm{b}} \frac{\hat{\boldsymbol{\eta}}}{\|\hat{\boldsymbol{\eta}}\|}-\boldsymbol{\beta}\right)
$$

Where $\boldsymbol{D}^{p}$ is the plastic stretching tensor, $\boldsymbol{D}_{\mathrm{s}}^{p}$ is the deviator component of $\boldsymbol{D}^{p},-D_{\mathrm{v}}^{p}$ is the volumetric component of $\boldsymbol{D}^{p}$, and \|\| represents its norms. $\stackrel{\boldsymbol{\beta}}{\text { in Eq. }}$ (A1-5) is the Green and Nahdhi's (1965) rate of $\boldsymbol{\beta}$. The parameter groups for the evolution rules in Eqs. (A1-3)-(A1-5) all consists of constants, and from their respective functions we may call $a, b, c, c_{\mathrm{s}}$ the degradation indices of structure, $m$ the degradation index of overconsolidation, $b r$ the rotational hardening index, and $m_{\mathrm{b}}$ the rotational hardening limit constant.

A new evolution rule for $R^{*}$ is proposed to replace Eq. (A1-3) for expressing structural upgradation, dividing the contribution of plastic deformation to the change of soil structure into the deviator of the plastic stretching $\sqrt{2 / 3} \mathbf{D}_{\mathrm{s}}^{p}$ and volumetric component $-D_{\mathrm{v}}^{p}$. The ratio between these terms is given by $c_{\mathrm{s}}\left(0 \leq c_{\mathrm{s}} \leq 1\right)$.

\section{The Associated Flow Rule and the Constitutive Equation}

Associated flow rule:

$$
\begin{aligned}
& \boldsymbol{D}^{p}=\lambda \frac{\partial f}{\partial T^{\prime}}, \\
& \lambda=\frac{\frac{\partial f}{\partial T^{\prime}} \cdot \stackrel{T}{ }^{\prime}}{J \frac{\mathrm{MD}}{p^{\prime}\left(\mathrm{M}^{2}+\eta^{* 2}\right)}\left(\mathrm{M}_{\mathrm{s}}^{2}-\eta^{2}\right)}>0
\end{aligned}
$$

Constitutive equation:

$$
{\stackrel{\circ}{T^{\prime}}}^{\prime} \boldsymbol{E D}-\Lambda E \frac{\partial f}{\partial T^{\prime}}
$$

where $\boldsymbol{E}$, is the elastic modulus tensor $\stackrel{\circ}{\prime}^{\prime}$ is the Green and Naghdi's (1965) rate of $\boldsymbol{T}^{\prime}$, and $\Lambda$ is the expression of plastic multiplier $\lambda$ in terms to stretching $\boldsymbol{D}$. Further, we can establish the relations

$$
\begin{aligned}
\mathrm{M}_{\mathrm{s}}^{2}= & \mathrm{M}_{\mathrm{a}}^{2}+b r \frac{4 \mathrm{M} \eta^{* 2}}{\mathrm{M}^{2}+\eta^{* 2}}\left(m_{\mathrm{b}} \eta^{*}-\sqrt{\frac{3}{2}} \hat{\boldsymbol{\eta}} \cdot \boldsymbol{\beta}\right) \\
& -\mathrm{MD}\left(\frac{U^{*}}{R^{*}} 2 \eta^{*}+\frac{U}{R} \sqrt{6 \eta^{* 2}+\frac{1}{3}\left(\mathrm{M}_{\mathrm{a}}^{2}-\eta^{2}\right)^{2}}\right)
\end{aligned}
$$

and

$$
\mathrm{M}_{\mathrm{a}}^{2}=\mathrm{M}^{2}+\zeta^{2}, \quad \zeta=\sqrt{3 / 2}\|\boldsymbol{\beta}\|
$$

The slope $M_{s}$ of the threshold between hardening and softening $q=\mathrm{M}_{\mathrm{s}} p^{\prime}$, obtained under loading conditions $\lambda>0$, varies according to structural degradation, loss of overconsolidation and development or loss of anisotropy, as well as with the current stress ratio. Similarly, the slope $M_{\mathrm{a}}$ of the threshold between plastic compression and expansion $q=M_{\mathrm{a}} p^{\prime}$ varies in response to the development or loss of anisotropy. For details, the reader is referred to Asaoka et al., 2002.

\section{APPENDIX 2: METHOD OF DETERMINATION OF MATERIAL CONSTANTS AND IN-SITU INITIAL CONDITIONS OF THE GROUND}

By considering ideal sampling paths with the least amount of disturbance, the series of stages from in-situ sampling up to test implementation (i.e., in-situ sampling $\rightarrow$ test sample preparation and setting in the apparatus $\rightarrow$ test commencement) can be simulated by the response of the SYS Cam-clay model. For example, the three types of mechanical tests that are subject to investigation in this paper can be simulated by the following stress paths:

(1) Constant strain rate consolidation test (refer to Fig. A2-1(1)):

From the in-situ condition (A), undrained unloading is carried out (sampling stage) up to the isotropic stress condition (B) while maintaining the water content. Subsequently, presuming swelling unloading within the consolidation ring, one-dimensional unloading is carried out (stage of sample set up) up to a sufficiently low stress (1.0 $\mathrm{kPa}$ ) condition $(\mathrm{C})$. This is followed by the one-dimensional consolidation (test).

(2) Undrained triaxial test (refer to Fig. A2-1(2)):

As in (1) above, undrained unloading is carried out from the in-situ condition (A) up to the isotropic stress condition (B) while maintaining the water content, after which, presuming the sample preparation stage, isotropic unloading is carried out (stage of sample set up) up to 1.0 $\mathrm{kPa}(\mathrm{C})$. Following this, isotropic consolidation is performed up to the specified constraint pressure (D), and the undrained shearing (test) is implemented.

(3) Unconfined compression test (refer to Fig. A2-1(3)):

As in (1) and (2) above, undrained unloading is carried out from the in-situ condition (A) up to the isotropic stress condition (B) while maintaining the water content to implement undrained shearing. The sensitivity ratios are determined from the strength ratios obtained by carrying out undrained shearing (test) from the condition where no skeleton structure exists $\left(\mathrm{B}^{\prime}\right)$ due to sufficient remolding while maintaining the water content constant.

In the case of soil samples that have been extracted from the same layer, application of the SYS Cam-clay model allows description of the soil by a set of initial insitu conditions and material constants irrespective of the testing conditions (stress path, hydraulic boundary, etc.). Therefore, by executing the computational simulation described above with respect to all the provided results of mechanical tests, it is possible to determine not only the material constants but also the initial in-situ conditions of 

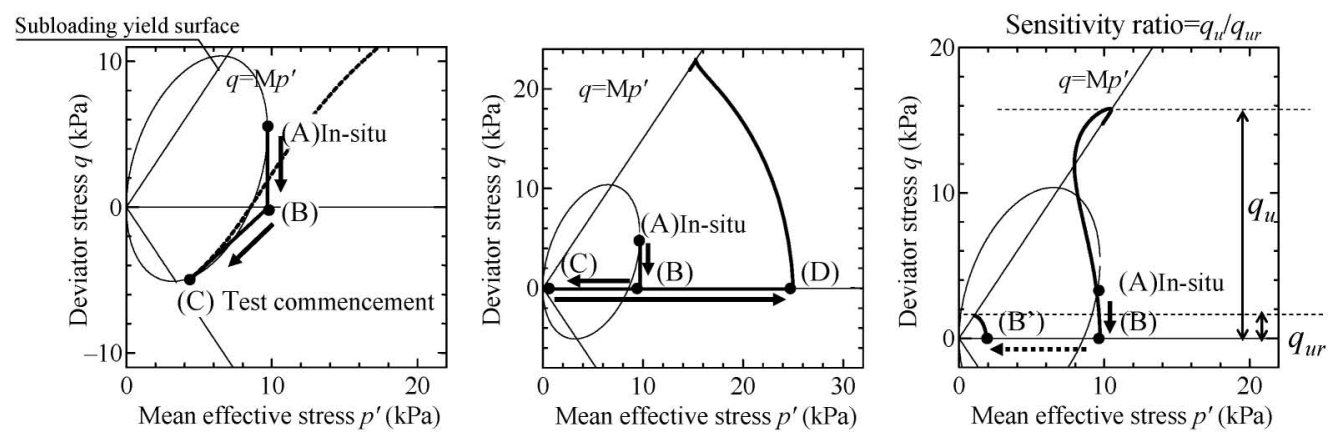

Fig. A2-1. Simulation of laboratory mechanical tests

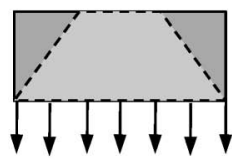

(A)

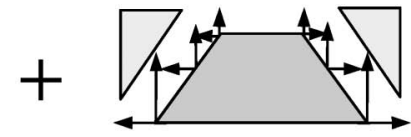

(B)

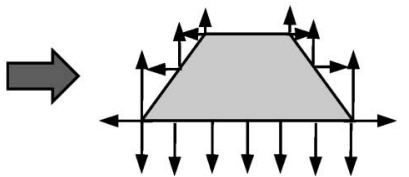

(C)

Fig. A3-1. Method of embankment element addition (element formation)

each soil layer.

\section{APPENDIX 3: EMBANKMENT LOADING (FINITE ELEMENT ADDITION) METHOD}

In this work, embankment loading has been expressed by the step-by-step addition of finite elements representing elasto-plastic sandy material. First, under the assumption that the embankment to be added exists under a gravitational field in a homogeneous state along the horizontal direction, its initial conditions were computed separately from the calculations for the ground. Then, without changing the stress states, etc. of the embankment and ground being loaded, the displacement boundary of the embankment's bottom face is converted into a stress boundary and linked to a designated position of ground. With respect to the embankment added here, its shape (trapezoidal element mesh in the current computation) has been preserved while stresses, etc. that are homogeneous in the horizontal direction have been distributed along the vertical depth direction starting from the added embankment's crest. This means that the periphery of the embankment is subjected to surface forces that are required to maintain the stress state, etc. in its interior. Therefore, it is necessary to determine such surface forces and remove them. In the current computation, removal of the surface forces acting on the periphery of the embankment and linking of the ground surface and embankment were conducted simultaneously, as illustrated in Fig. A3-1. In other words, at the joint interface between the embankment's bottom face and ground, the mass of the embankment (Fig. A3-1(A)) was made to act on the ground. Simultaneously, vertical forces equivalent to the mass of the soil lying above the embankment slopes and lateral forces equivalent to the constraint acting from the sides (Fig. A3-1(B)) were made to act on the embankment slopes in the opposite direction.

\section{REFERENCES}

1) Asaoka, A., Nakano, M. and Noda, T. (1994): Soil-water coupled behaviour of saturated clay near/at critical state, Soils and Foundations, 34(1), 91-105.

2) Asaoka, A., Noda, T. and Fernando, G. S. K. (1997): Effects of changes in geometry on the linear elastic consolidation deformation, Soils and Foundations, 37(1), 29-39.

3) Asaoka, A., Nakano, M. and Noda, T. (2000): Superloading yield surface concept for highly structured soil behaviour, Soils and Foundations, 40(2), 99-110.

4) Asaoka, A., Noda, T., Yamada, E., Kaneda, K. and Nakano, M. (2002): An elasto-plastic description of two distinct volume change mechanisms of soils, Soils and Foundations, 42(5), 47-57.

5) Asaoka A. (2003): Consolidation of clay and compaction of sand-An elasto-plastic description-, Keynote lecture, Proc. of 12th Asian Regional Conf. on Soil Mechanics and Geotechnical Engineering, Leung et al., Singapore, 2, 1157-1195.

6) Asaoka, A. and Noda, T. (2007): All soils all states all round geoanalysis integration, International Workshop on Constitutive Modelling-Development, Implementation, Evaluation, and Application, Hong Kong, China, 11-27.

7) Green, A. E. and Naghdi, P. M. (1965): A general theory of an elastic-plastic continuum, Archive for Rational Mechanics and Analysis, 18, 251-281.

8) Hashiguchi K. (1978): Plastic constitutive equations of granular materials, Proc. of US-Japan Seminar on Continuum Mechanics and Statistical Approaches in the Mechanics of Granular Materials (eds. by Cowin, S. C. and Satake, M.), Sendai, JSSMFE, 321-329.

9) Hashiguchi, K. (1989): Subloading surface model in unconventional plasticity, Int. Journal of Solids and Structures, 25, 917-945.

10) Hashiguchi, K. and Chen, Z.-P. (1998): Elasto-plastic constitutive equations of soils with a subloading surface and rotational hardening, Int. J. Numer. Anal. Meth. Geomech., 22, 197-227.

11) Lambe, T. W. (1973): Predictions in soil engineering, Geotechnique, 23(2), 149-202.

12) Nakai, T. (2002): Prediction of lateral displacement and lateral flow 
of ground, Tsuchi-to-Kiso, The Japanese Geotechnical Society, 50(2), 529, 4-6 (in Japanese).

13) Nakano, M., Nakai, K., Noda, T. and Asaoka, A. (2005): Simulation of shear and one-dimensional compression behaviour of naturally deposited clays by Super/subloading Yield Surface Cam-clay model, Soils and Foundations, 45(1), 141-151.

14) Nakano, M., Yamada, E. and Noda, T. (2008): Ground improvement of intermediate reclaimed land by compaction through cavity expansion of sand piles, Soils and Foundations, 48(5), 653-671.

15) Noda, T., Yamada, S. and Asaoka, A (2005a): Elasto-plastic behaviour of naturally deposited clay during/after sampling, Soils and Foundations, 45(1), 51-64.

16) Noda, T., Asaoka, A., Nakano, M., Yamada, E. and Tashiro, M. (2005b): Progressive consolidation settlement of naturally deposited clayey soil under embankment loading, Soils and Foundations, 45(5), 39-51.

17) Noda, T., Asaoka A. and Yamada, S. (2007): Some bearing capacity characteristics of a structured naturally deposited soil, Soils and Foundations, 47(2), 285-301.

18) Noda, T., Asaoka, A. and Nakano, M. (2008): Soil-water coupled finite deformation analysis based on a rate-type equation of motion incorporating the SYS Cam-clay model, Soils and Foundations, 48(6), 771-790.
19) Noda, T., Takeuchi, H., Nakai, K. and Asaoka, A. (2009): Co-seismic and post-seismic behaviour of an alternately layered sand-clay ground and embankment system accompanied by soil disturbance, Soils and Foundations, 49(5), 739-756.

20) Roscoe, K. H. and Burland, J. B. (1968): On the generalized stressstrain behaviour of 'wet' clay, Engineering Plasticity (eds. by Heyman, J. and Leckie, F. A.), Cambridge University Press, 535-609 pp.

21) Sekiguchi, H. and Ohta, H. (1977): Induced anisotropy and time dependency in clays, Constitutive Equations of Soils (Proc. 9th ICSMFE, Spec. Session 9), Tokyo, 229-238.

22) Skempton, A. W. (1994): Notes on The Compressibility of Clays, Quart. J. Geol. Soc., London, C, 119-135.

23) Takeuchi, H., Takaine, T. and Noda, T. (2006): Effect of nonlinearity in geometry on the consolidation deformation of saturated clay soil, Journal of Applied Mechanics, JSCE, 9, 39-550 (in Japanese).

24) Wojciech, W., Rolf, L., Alojzy, S., Jan, H., Jozef, M., Kazimierz, G., Zbigniew, L. and Ulf, B. (1988a): Two stage-constructed embankments on organic soils, Swedish Geotechnical Report, 32.

25) Wojciech, W., Rolf, L., Alojzy, S., Jan, H., Zbigniew, L. and Ulf, B. (1988b): Full-scale failure tests on a stage-constructed test fill on organic soil, Swedish Geotechnical Report, 36. 